\title{
The use of myocutaneous flaps by general surgeons
}

\author{
S.M. Allan, C.R.P. Williams, R.M. Heddle, D.B. Jackson and R.E.C. Collins
}

Kent and Canterbury Hospital, Canterbury CT1 3NG, UK.

\begin{abstract}
Summary: This is a study of the use of myocutaneous flaps by general surgeons in a district general hospital over a 5 year period, and shows that such work can be satisfactorily performed by general surgeons.
\end{abstract}

\section{Introduction}

Not infrequently general surgeons find themselves required to close large tissue defects caused by surgery, disease, trauma or radionecrosis. The following series of patients reveals the nature of tissue replacement problems that presented to three general surgeons in a 5 year period at The Kent and Canterbury Hospital. The majority of cases underwent breast reconstruction and the management of pressure sores and their resultant tissue deficits. Previously such cases required referral to busy plastic surgeons, but the techniques of tissue reconstruction were felt to be applicable for use by the general surgeons of this unit. This paper is a review of the first 5 years experience.

\section{Patients and methods}

During the course of a 5 year period 43 cases presented to three general surgeons. Twenty seven of these cases were for breast or chest wall reconstruction, consisting of 8 cases of breast reconstruction for previous radical mastectomy. A further 15 cases consisted of combined simultaneous mastectomy and breast reconstruction as a primary treatment for breast carcinoma. In addition there were four cases of chest wall reconstruction for locally recurrent breast carcinoma.

Ten cases of pressure sores related to a variety of neuropathic and recumbency problems occurring in the ischiorectal areas. There were also three cases of tissue deficit in the perineum requiring myocutaneous flap closure subsequent to radical surgical resection of perineal malignancy. ${ }^{8}$ In addition there were two cases of longstanding fistulae subsequent to previous laryngotracheal surgery and one problem of tissue deficit in the orbit subsequent to radical exenteration for malignant melanoma that required the use of a myocutaneous flap for treatment. ${ }^{7}$
The myocutaneous flaps that were used in this series are all long established ${ }^{4}$ and well described. ${ }^{1,2}$ The majority of the cases were dealt with using just three flaps, the latissimus dorsi, ${ }^{3}$ the transverse rectus ${ }^{5}$ and the gluteus maximus flaps ${ }^{6}$ (Table I). The following four cases are selected examples from the series to demonstrate the scope of treatment that can be provided by the general surgeon.

Case 1 - latissimus dorsi flap for breast reconstruction

A 63 year old woman with a previous right sided radical mastectomy for carcinoma, presenting with local tumour recurrence in her scar and chest wall. This was widely excised locally, including involved chest wall and underlying pleura, with the proposed flap viability having been established by angiography prior to surgery. Prolene mesh was used to close the defect in the chest wall with a standard latissimus dorsi myocutaneous flap closing the tissue deficit above. Full primary healing without complications was achieved.

Table I Patients and procedures

\begin{tabular}{lrlr}
\hline Useage & Number & \multicolumn{1}{c}{ Flap type } \\
\hline Breast reconstruction & 27 & Latissimus dorsi & 14 \\
& & Transverse rectus & 13 \\
Bedsores (ischiosacral) & 10 & Gluteus maximus & 6 \\
& & Posterior thigh flap & 2 \\
& & Gracilis & 1 \\
Perineal reconstruction & \multirow{2}{*}{$\begin{array}{l}\text { Biceps femoris } \\
\text { Laryngotracheal defects }\end{array}$} & Gracilis & 1 \\
& 2 & Tensor fascia lata & Sternomastoid \\
Closure of orbit & 1 & Platysma & 1 \\
& & Sternomastoid & 1
\end{tabular}

The Fellowship of Postgraduate Medicine, 1989 


\section{Case 2 - gluteus maximus flap for bedsore}

An 80 year old paraplegic man with a sacral bedsore which failed to heal with attempted debridement and suturing with primary closure. He required a left sided gluteus maximus island flap that was raised and tunnelled into the defect with good result. No complications in wound healing occurred.

\section{Case 3 - platysma flap for closure of tracheostomy fistula}

A 20 year old man with laryngeal papillomatosis who required surgery and the formation of a tracheotomy at the age of two presented with a chronically discharging fistula despite several previous attempts at closure. He required a left platysma flap to close the 8 centimetre defect following excision of the scar and fistula. This case was complicated by a serous ooze from the flap margin, which settled, with complete closure of the wound on conservative management after 2 weeks without further complications.

\section{Case 4 - simultaneous mastectomy and transverse} rectus reconstruction

A 42 year old woman who had undergone previous lumpectomy and radiotherapy for breast carcinoma then presented at follow-up with recurrent tumour in the same breast. In view of the first tumour being medially positioned within the breast and the second tumour being laterally placed it was thought that this was a second primary despite previous irradiation. Simultaneous mastectomy and breast reconstruction was carried out using a transverse rectus myocutaneous flap, with excellent result. Subsequent nipple and aerolar formation was also carried out by tissue sharing from the other breast.

\section{Results}

In the series of 43 flaps, a total of 30 had a completely successful uncomplicated outcome. A total of 13 had a postoperative complication during their treatment, but all of these cases had a successful final outcome. Whilst not a single flap in the series was lost, three partial flap losses (less than $15 \%$ of total flap area) occurred, all of which did require surgical revision to achieve a satisfactory result. One patient, who had a massive tissue deficit requiring two separate myocutaneous flaps to close the defect, did require secondary adjustment of the flaps to effect a good result. One patient requiring a larger than normal sized flap to close the tissue defect resultant from wide excision of recurrent carcinoma after mastectomy and radiotherapy needed partial thickness grafting of the donor site. This became infected and took 6 weeks to achieve full healing. Two patients had wound infections, one of which required a subsequent split skin graft to achieve satisfactory healing. One patient had a wound haematoma that required surgical drainage. Finally there were five patients who had a degree of wound separation after operation, but none of these five needed further surgery, all obtaining satisfactory wound closure eventually.

\section{Discussion}

The bulk of problems requiring closure presenting at a district general hospital, are breast, chest wall and ischiorectal defects.

The single vascular pedicle and relatively constant anatomical nature of the basic flaps give them a great surgical versatility. With the latissimus dorsi, tranverse rectus and gluteus maximus flaps, a large proportion of the problems presenting can be safely dealt with by the general surgeon. The mobilization of a myocutaneous flap for tissue replacement is no more demanding than the mobilization and anastomosis of an intra-abdominal composite flap such as the left colon on the marginal artery of Drummond in an anterior resection. Despite recent discussion, often heated and protective of the specialists,, 10 we would argue that our results, both in the successful outcome and acceptable level of complications should encourage the general surgeon to deal with a good proportion of cases presenting at a district general hospital. This would allow our plastic surgical colleagues to concentrate on the more demanding and specialized problems of reconstructive surgery.

3. Salmon, R.J., Razaboni, R. \& Soussaline, M. The use of the lattissimus dorsi musculocutaneous flap following recurrence of cancer in irradiated breasts. Br J Plast Surg 1988, 41: $41-44$.
1. Tobin, G.R. Myocutaneous and muscle flap reconstruction of problem wounds. Surg Clin North Am 1984, 64: 667-681.

2. Mathes, S.J. \& Nahai, F. Clinical Applications for Muscle and Myocutaneous Flaps. C.V. Mosby, St Louis Missouri, USA, 1982. 
4. d'Este, S. La technique de L'amputation De La Mamelle pour carcinome mammaire. Rev Chir 1912, XLV: $164-210$.

5. Georgiade, G.S., Voci, V.E., Reifkohl, R.\& Scheflan, M. Potential problems with the transverse rectus abdominus myocutaneous flap in breast reconstruction and how to avoid them. Br J Plast Surg 1984, 37: 121-125.

6. Bostwick, J., Hill, H.L. \& Nahai, F. Repair in the lower abdomen, groin or perineum with myocutaneous or omental flaps. Plast Reconstr Surg 1979, 63: 186.

7. Marx, R.E. \& McDonald, D.K. The sternocleidomastoid muscle as a muscular or myocutaneous flap for oral and facial reconstruction. J Oral Maxillofac Surg 1985, 43, $155-162$.
8. Kennedy, C.L., Breach, N.M., Shepherd, J.H. \& Hendry, W.F. The use of myocutaneous flaps following radical excision of the external genitalia. Br J Urol 1987, $C$ 59: $272-276$.

9. Nash, A.G. \& Hurst, P.A. Central breast carcinoma treated by simultaneous mastectomy and latissimus dorsi? flap reconstruction. $B r J$ Surg 1983, 70: 654-655.

10. Nash, A.G. \& Taylor, P.R. Breast reconstruction after failed conservation. Ann $R$ Coll Surg Engl 1985, 67:Ф 303-305 